\title{
Technology of Extracting Kiwi Fruit Seed Oil with Ultrasonic-Assisted Enzyme and Response Surface Method
}

\author{
Zhi Zhang1*, Mengting Pan1, Dongmin Liu ${ }^{2}$ \\ ${ }^{1}$ Northeast Forestry University, Harbin, China \\ ${ }^{2}$ Dujiangyan Tianyi Kiwi Fruit Industrial Technology Institute, Dujiangyan, China \\ Email: *mlbsabc@sina.com
}

Received 25 June 2016; accepted 25 July 2016; published 28 July 2016

Copyright (C) 2016 by authors and Scientific Research Publishing Inc.

This work is licensed under the Creative Commons Attribution International License (CC BY). http://creativecommons.org/licenses/by/4.0/

c) (7) Open Access

\begin{abstract}
Taken kiwi fruit as raw material, this paper extracted kiwi fruit seed oil with ultrasonic-assisted enzyme, researched the influence of factors such as liquid-to-solid ratio, granularity, type of enzyme, ultrasonic power, treating time, enzymolysis temperature, enzymolysis time, $\mathrm{pH}$ and enzyme additive on oil extraction, and optimized the extracting technology of kiwi fruit seed oil with response surface method. The result shows that the best technical parameter is: material granularity: 60, liquid-to-solid ratio: $1: 10(\mathrm{~g} / \mathrm{mL})$, ultrasonic power: $400 \mathrm{~W}$, treating time: $30 \mathrm{~min}$, enzyme amount: $2.50 \%$, pH: 9.2 , enzymolysis temperature: $53^{\circ} \mathrm{C}$, enzymolysis time: $2.80 \mathrm{~h}$; and the extracting ratio under such condition is $92.57 \%$.
\end{abstract}

\section{Keywords}

Kiwi Fruit Seed Oil, Ultrasonic Wave, Aqueous Enzymatic Method

\section{Introduction}

Kiwi fruit in Sichuan Hongyang belongs to Actinidia, Actinidiaceae, which can normally grow and bear fruit on both high and low altitude. Red kiwi fruit is a kind of rare good variety based on seedling-selection of wild kiwi fruit. It has radial purple lines on the transverse section along the core, and thus it's called as "Hongyang kiwi fruit”. The size of kiwi fruit seed is small, and its shape is like sesame, containing $22 \%-24 \%$ oil, rich in unsaturated fatty acid like linolenic acid and inoleic acid, in which the content of linolenic acid is as high as $64.1 \%$. It has multiple functions in reducing blood fat and blood pressure, restraining thrombus, protecting eyesight and

${ }^{*}$ Corresponding author.

How to cite this paper: Zhang, Z., Pan, M.T. and Liu, D.M. (2016) Technology of Extracting Kiwi Fruit Seed Oil with Ultrasonic-Assisted Enzyme and Response Surface Method. Food and Nutrition Sciences, 7, 807-816. 
improving intelligence, which has great development prospect [1].

The aqueous enzymatic method is a king of new technology of oil extraction which is widely researched recently. Compared to traditional technology, it has gentle condition and needs little energy, and the oil extracted has good quality [2]. At present, there has been report of extracting sweet almond oil [3], sunflower seed oil [4], and walnut kernel oil [5] with aqueous enzymatic method. There has been report of application of ultrasonic extraction technology in extraction of kiwi fruit seed. Li Jiaxing [6] and his partners researched the technology of extracting kiwi fruit seed oil with ultrasonic with petroleum ether as extraction solvent. Zhang Guangdong [7] and his partners optimized the technology of extracting kiwi fruit seed oil with ultrasonic via uniform design. Compared to traditional mechanical compression method, ultrasonic method has higher extraction ratio and takes less time.

Thus, this test optimizes ultrasonic-assisted enzyme with response surface method, combines the two technologies and makes them fully complement each other, and improves the oil yield of kiwi fruit seed and oil quality for reference of comprehensive development and use of kiwi fruit.

\section{Testing Method}

\subsection{Extracting Technology Course of Kiwi Fruit Seed Oil}

1) Extracting technology course

Kiwi fruit seed $\rightarrow$ smash $\rightarrow$ sieve $\rightarrow$ ultrasonic treatment $\rightarrow$ adjust liquid-to-solid ratio $\rightarrow$ mix $\rightarrow$ enzymolysis $\rightarrow$ enzyme deactivation $\left(90^{\circ} \mathrm{C}, 10 \mathrm{~min}\right) \rightarrow$ centrifugation $\rightarrow$ solvent extraction $\rightarrow$ rotary evaporation $\rightarrow$ kiwi fruit seed oil $\rightarrow$ analysis and test.

2) Operational method

Accurately weigh and put 20 gram of dried and smashed kiwi fruit seed powder in to the conical flask, add distilled water according to corresponding liquid-to-solid ratio, conduct ultrasonic treatment, adjust $\mathrm{pH}$, add moderate enzyme, conduct full enzymolysis for some time in proper temperature, water bath for $10 \mathrm{~min}$ in $90^{\circ} \mathrm{C}$ to destroy the added enzyme, centrifuge for $30 \mathrm{~min}$ in condition of $3000 \mathrm{r} / \mathrm{min}$, extract the upper layer of clear oil with $20 \mathrm{~mL}$ of petroleum ether for 3 times, mix the extract liquor, remove the petroleum ether via vacuum rotary evaporation, and then the kiwi fruit seed oil is produced, accurately weigh it and calculate the oil extraction ratio:

$$
\text { Oil extraction ratio }(\%)=W_{1} /\left(W_{1} X_{1}\right) \times 100 \%
$$

In the formula, $W_{1}$ : weight of kiwi fruit seed, g; $W_{2}$ : weight of kiwi fruit seed oil extracted via enzymolysis, g; $X_{1}$ : oil content of kiwi fruit seed, \%.

\subsection{Test Design}

1) Single-factor test design

Determination of enzyme type: select cellulase, neutral protease, acid proteinase, alkaline protease and pectinase, the additive amount is $2.0 \%$, the ultrasonic power is $400 \mathrm{~W}$, the time is $30 \mathrm{~min}$, the granularity of raw material is 40 , liquid-to-solid ratio is $1: 10(\mathrm{~g} / \mathrm{mL})$, conduct full enzymolysis for $2 \mathrm{~h}$ in the most suitable $\mathrm{pH}$ and temperature, observe the influence of different zymin on oil extraction ratio.

Selection of liquid-to-solid ratio: select alkaline protease, $\mathrm{pH}$ is 9.0 , temperature is $55^{\circ} \mathrm{C}$, the other conditions are as above, the liquid-to-solid ratio is respectively $1: 4,1: 6,1: 8,1: 10,1: 12,1: 14$, confirm the best liquid-tosolid ratio.

Granularity of raw material: liquid-to-solid ratio is $1: 10(\mathrm{~g} / \mathrm{mL})$, the other conditions are as above, conduct enzymolysis with granularity of 20,40,60, 80, 100 and 120, confirm the best granularity of raw material.

Ultrasonic power: granularity of raw material is 60 , the other conditions are as above, the power is $100 \mathrm{~W}, 200$ $\mathrm{W}, 300 \mathrm{~W}, 400 \mathrm{~W}$ and $500 \mathrm{~W}$, confirm the best power.

Ultrasonic time: the power is $400 \mathrm{~W}$, the other conditions are as above, treat for $10 \mathrm{~min}, 20 \mathrm{~min}, 30 \mathrm{~min}, 40$ min and $50 \mathrm{~min}$, confirm the best treatment time.

Additive amount of enzyme: ultrasonic treatment time is $30 \mathrm{~min}$, the other conditions are as above, add protease of $0.5 \%, 1.0 \%, 1.5 \%, 2.0 \%, 2.5 \%$ and $3 \%$, confirm the best additive amount.

Enzymolysis temperature: the additive amount of enzyme is $2.0 \%$, the other conditions are as above, the en- 
zymolysis temperature is respectively $40^{\circ} \mathrm{C}, 45^{\circ} \mathrm{C}, 50^{\circ} \mathrm{C}, 55^{\circ} \mathrm{C}, 60^{\circ} \mathrm{C}$ and $65^{\circ} \mathrm{C}$, confirm the best extracting temperature.

Extracting time: the enzymolysis temperature is $55^{\circ} \mathrm{C}$, the other conditions are as above, the enzymolysis time is respectively $1 \mathrm{~h}, 1.5 \mathrm{~h}, 2 \mathrm{~h}, 2.5 \mathrm{~h}, 3 \mathrm{~h}$ and $3.5 \mathrm{~h}$, confirm the best enzymolysis time.

$\mathrm{pH}$ : the enzymolysis temperature is $55^{\circ} \mathrm{C}$, the other conditions are as above, adjust $\mathrm{pH}$ in $6,7,8,9,10$ and 11 , confirm the best $\mathrm{pH}$.

2) Extracting technology of kiwi fruit seed oil with response surface method

Based on single-factor research, the granularity of material is 60 , liquid-to-solid ratio is $1: 10(\mathrm{~g} / \mathrm{mL})$, treat with 400-W ultrasonic power for 30 min, select additive amount of enzyme (X1), $\mathrm{pH}(\mathrm{X} 2)$, enzymolysis temperature (X3) and enzymolysis time (X4) as four independent variables, the oil extracting ratio (Y) as response, design response experiment according to the design principle of the central combination, see the test factor and level in Table 1.

\section{Result and Analysis}

\subsection{Single-Factor Test}

1) Selection of enzyme type

It can be seen from the Figure 1 that the blank group is not treated with enzyme and the oil extraction ratio is the lowest, after adding different enzyme, the oil extraction increases, among which the alkaline protease has the best effect, and the cellulase, acid proteinase and pectinase have relatively bad effect. This is because the plant's cell wall mainly consists of cellulose, hemicellulose and pectin, the oil in kiwi fruit seed mostly exists in the form of lipoprotein, although cellulose and pectin is hydrolyzed, the kiwi fruit seed protein is stable in acid condition. There are many differences among the types and structures of plant protein, and the specificity of enzyme is strong, only select suitable enzyme can hydrolyze the protein. However, alkaline protease can better match with the basic group of kiwi fruit seed protein, cut it into micromolecule peptide, increase its solubleness, release oil, achieve the target of enzymolysis. Thus it selects alkaline protease.

2) Determination of liquid-to-solid ratio

It can be seen from Figure 2 that moderate water is good for oil extraction, when the liquid-to-solid ratio is within the range of 1:4 - 1:10 (g/Ml), with the increase of liquid-to-solid ratio, the oil extraction rate increases

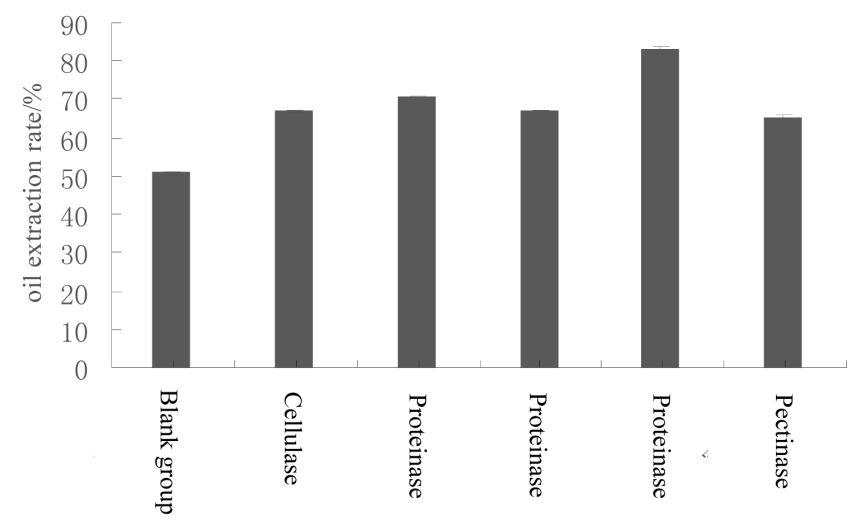

Figure 1. The effect of enzyme on extraction of kiwi fruit seed oil.

Table 1. Test factor and level table.

\begin{tabular}{ccccc}
\hline \multirow{2}{*}{ Level } & \multicolumn{3}{c}{ Factor } \\
\cline { 2 - 5 } & X1: additive amount of enzyme/\% & X2: $\mathrm{pH}$ & X3: enzymolysis temperature/ ${ }^{\circ} \mathrm{C}$ & X4: enzymolysis time/h \\
\hline-1 & 1.5 & 8.5 & 50 & 2 \\
0 & 2 & 9 & 55 & 2.5 \\
1 & 2.5 & 9.5 & 60 & 3 \\
\hline
\end{tabular}




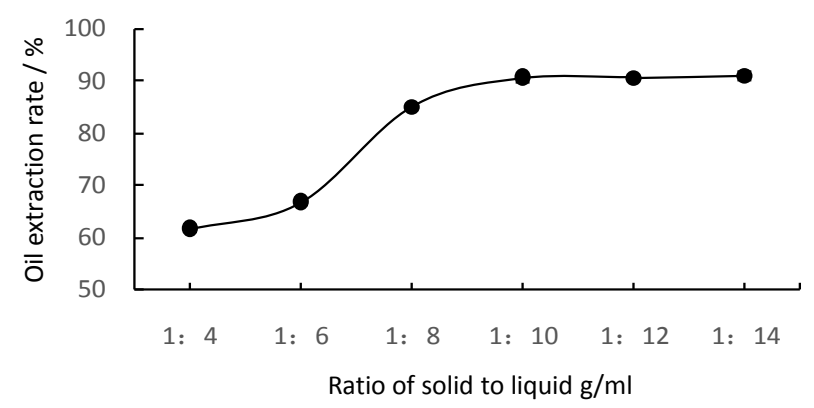

Figure 2. The effects of the ratio of solid to liquid on extraction of kiwi fruit seed oil.

obviously, if the water is too little, the raw material can not imbibe it and it can't achieve the effect of enzymolysis, however, if the water is too much, it will increase the extracting cost. When the liquid-to-solid ratio is 1:10 $(\mathrm{g} / \mathrm{mL})$, the extraction rate of kiwi fruit seed oil is relatively high, and the oil extraction rate does not increase obviously if water is kept adding. Comprehensively consider the factors such as extraction rate and energy consumption, the best liquid-to-solid ratio of enzymolysis is around 1:10.

3) Determination of granularity

It can be seen from Figure 3 that in the range of 20 - 60 meshes, with the increase of size, the oil extraction rate increases obviously, because the finer the granularity is, the better enzyme can contact with the raw material, which is good for oil extraction. When the comminution degree is larger than 60 meshes, the finer the granularity is, the higher the comminution degree, the higher viscosity of the feed liquid, the severer emulsification degree, which is adverse to fat separation [8]. Thus, the best granularity of material is 60 meshes.

4) Determination of ultrasonic power

It can be seen from Figure 4 that after treatment, the ultrasonic can obviously improve the extraction rate of kiwi fruit seed oil, and with the increase of ultrasonic power, the extraction rate of kiwi fruit seed oil presents a trend of gradually increasing. When the ultrasonic power exceeds $400 \mathrm{~W}$, the extraction rate of kiwi fruit seed oil reaches peak, after that the extraction reduces with the increase of ultrasonic power. This is because the local heating effect of high-frequency ultrasonic causes the deterioration of protein, and influences the exudation of oil and causes severer emulsification of the oil layer and lowers the extraction rate [9]. Thus, the best ultrasonic power is $400 \mathrm{~W}$.

5) Determination of ultrasonic contact time

It can be seen from Figure 5 that with the extension ultrasonic contact time, the extraction rate of kiwi fruit seed oil gradually increases, and when the ultrasonic contact time is $30 \mathrm{~min}$, the extraction rate of kiwi fruit seed oil reaches peak, after that, the extraction rate of kiwi fruit seed oil declines with the increase of ultrasonic contact time. Thus, the best ultrasonic contact time is 30 min.

6) Determination of enzyme amount

The enzyme amount has a great influence on enzymolysis effect. If the enzyme is too little, there is not enough enzyme to combine with the substrate, which makes the reaction speed low and the it will not fully react, thus the extraction rate of kiwi fruit seed oil is influenced. It can be seen from Figure 6 that when the enzyme amount is $0.5 \%$, it obviously cannot reach the enzymolysis requirement and the reaction is not complete. When the enzyme amount increases to $2.5 \%$ from $1 \%$, the oil extraction rate increases greatly, it can be basically confirmed that when the enzyme amount is around $2.5 \%$, it can fully digest protein, and the oil extraction rate does not increase obviously when it is kept adding, comprehensively consider the factors such as extraction rate and experiment cost, the best enzyme amount is around $2.5 \%$.

7) Determination of enzymolysis temperature

It can be seen from Figure 7 that then the temperature increases to $55^{\circ} \mathrm{C}$ from $40^{\circ} \mathrm{C}$, the enzymolysis effect becomes better, and the oil extraction rate also increases, when the temperature is around $55^{\circ} \mathrm{C}$, which is the best range for enzyme, and it can well effect the protein-lipid complex, and the oil can well release. With the continuous increase of temperature, part of enzyme is inactivated and the enzymolysis declines, consequently the oil extraction rate also declines, at the same time, if the temperature is too high, it will cause too high peroxide value of the oil, thus the best enzymolysis temperature is around $55^{\circ} \mathrm{C}$.

8) Determination of enzymolysis time 


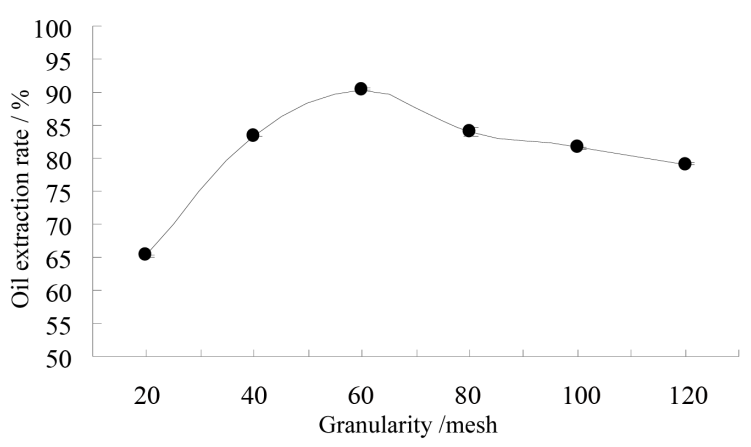

Figure 3. The effects of granularity of on extraction of kiwi fruit seed oil.

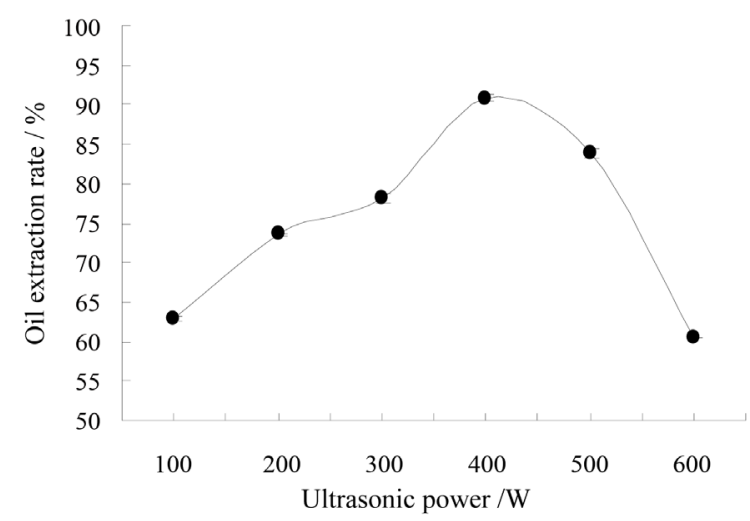

Figure 4. The effects of ultrasonic power on extraction of kiwi fruit seed oil.

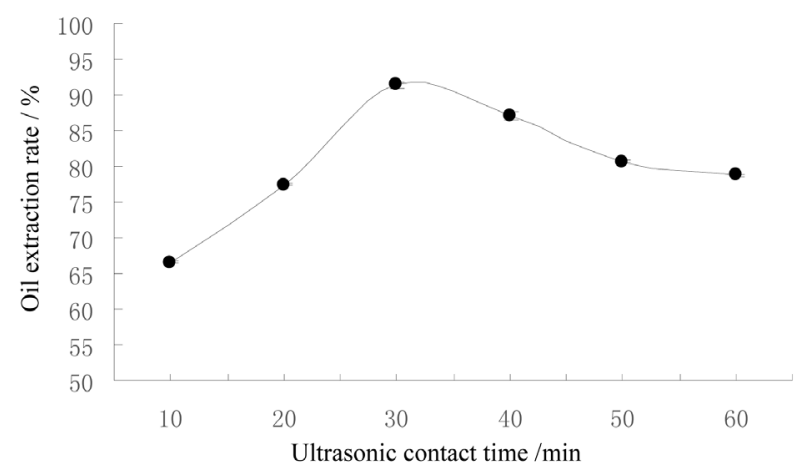

Figure 5. The effects of ultrasonic contact time on extraction of kiwi fruit seed oil.

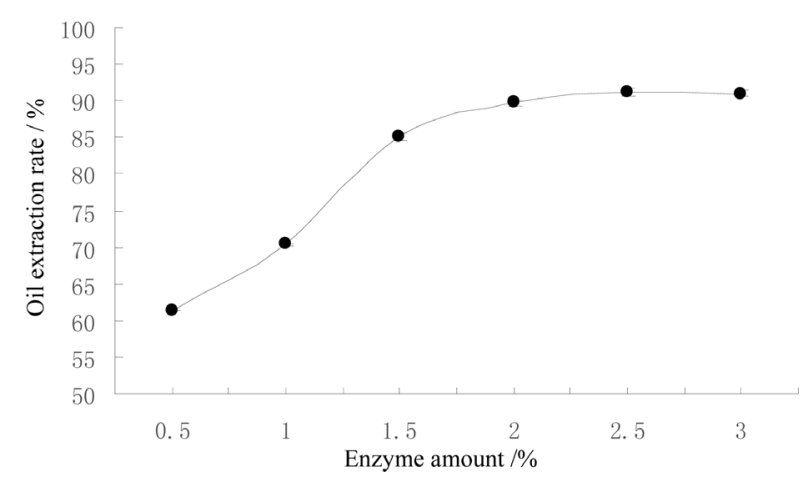

Figure 6. The effects of the amount of alkaline protease on extraction of kiwi fruit seed oil. 


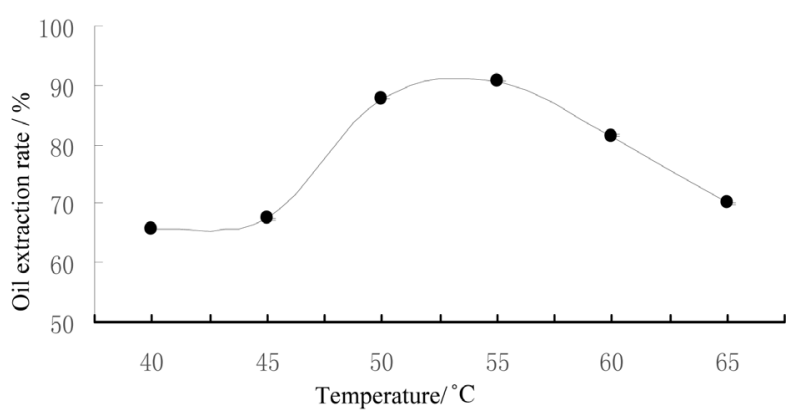

Figure 7. The effect of temperature on extraction of kiwi fruit seed oil.

Select proper extracting time can reduce workload during production, and reduce energy consumption. It can be known from Figure 8 that if the time is too short, not enough for enzymolysis, the reaction is not complete. With the increase of enzymolysis time, the extraction rate of kiwi fruit seed oil also keeps increasing, but after $2.5 \mathrm{~h}$, the extraction rate of kiwi fruit seed oil declines, at the same time, the increase of time leads to too high peroxide value if the kiwi fruit seed oil, and the color will also turn turbid, the oil extraction rate also declines. Based on comprehensive consideration, the best enzymolysis time is around $2.5 \mathrm{~h}$.

9) Determination of $\mathrm{pH}$

The change of $\mathrm{pH}$ will change the electriferous state of enzyme molecule and substrate molecule, influence the combination of enzyme molecule and substrate molecule. Too high or too low pH will influence the structure of enzyme and reduce enzymolysis effect. It can be seen from Figure 9 that if the $\mathrm{pH}$ is too low, it can not reach the best condition for enzymolysis, so the oil extraction rate is not high; if $\mathrm{pH}$ is too high, the enzymatic activity declines, the reaction is not complete, at the same time, the oil will react with excessive alkali, which will also lower the oil extraction rate, when $\mathrm{pH}$ is around 9.0, the oil extraction rate remains in a high level, thus the best $\mathrm{pH}$ for enzymolysis is around 9.0.

\subsection{Extracting Technology with Response Surface Method}

According to the result of single-factor test, confirm the best level range of all the factors, conduct response surface test design, research the influencing law of all the enzymolysis parameters on the observed index and get the best condition of enzymolysis. Select cellulase, the granularity is 60 , the liquid-to-solid ratio is $1: 10$ (g/mL), ultrasonic power is $400 \mathrm{~W}$, treating time is $30 \mathrm{~min}$, take enzyme amount (X1), pH (X2), enzymolysis temperature (X3) and enzymolysis time (X4) as independent variables, take extraction rate is response value, design corresponding test according to central combination principle [10]. See the scheme and result of the response surface in Table 2.

\subsection{Analysis of Parameters' Response Surface on Extraction Rate of Kiwi Fruit Seed Oil}

Conduct quadratic linear regression fitting the tested data in Table 3 with Design-expert 8.0.6, and gets the mathematical model:

$$
\begin{aligned}
\mathrm{Y}= & 91.44+3.07 \mathrm{X} 1+0.57 \mathrm{X} 2-3.38 \mathrm{X} 3+0.59 \mathrm{X} 4-0.61 \mathrm{X} 1 \mathrm{X} 2-1.62 \mathrm{X} 1 \mathrm{X} 3+2.59 \mathrm{X} 1 \mathrm{X} 4 \\
& -2.10 \mathrm{X} 2 \mathrm{X} 3-1.39 \mathrm{X} 2 \mathrm{X} 4-0.19 \mathrm{X} 34-3.92 \mathrm{X} 12-2.92 \mathrm{X} 22-5.28 \mathrm{X} 32-1.45 \mathrm{X} 42
\end{aligned}
$$

It can be seen from the Table 3 that the model is extremely significant $(P<0.01)$, it can be known from analysis of variance that correlation coefficient of model is R2 $=0.9592$, adjusted determination coefficient Radj $2=$ 0.9183, and the lack of fit is not obvious $(P>0.05)$, which means the model's fitting degree is good, the test error is small, the mathematical fitting model is very close to the measured value in the test, which has high credibility and accuracy, the model is founded [11].

It can be seen from Table 3 that first terms X1 and X3, quadratic terms X12, X22 and X32 and interaction terms X1X4 and X2X3 all perform extremely significantly, and the interaction terms X1X3 and quadratic term X42 performs significantly, which means enzyme amount, enzymolysis temperature and interaction all influence the extraction rate significantly, and the order of influencing factors is: enzymolysis temperature $>$ enzyme amount $>$ enzymolysis time $>\mathrm{pH}$. 


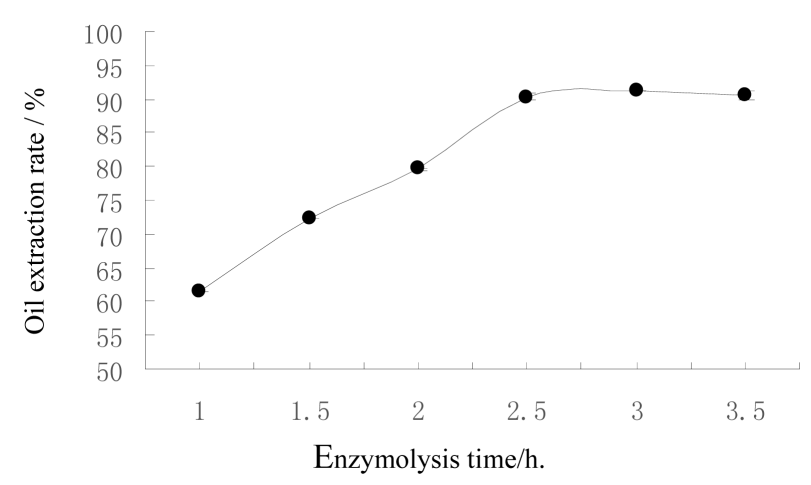

Figure 8. The effects of time on extraction of kiwi fruit seed oil.

Table 2. Response surface Box-Behnken arrangement and experimental results.

\begin{tabular}{|c|c|c|c|c|c|}
\hline Test number & $\mathrm{X} 1$ & $\mathrm{X} 2$ & X3 & $\mathrm{X} 4$ & Extraction rate/\% \\
\hline 1 & -1 & -1 & 0 & 0 & 86.58 \\
\hline 2 & 1 & -1 & 0 & 0 & 88.49 \\
\hline 3 & -1 & 1 & 0 & 0 & 89.69 \\
\hline 4 & 1 & 1 & 0 & 0 & 90.89 \\
\hline 5 & 0 & 0 & -1 & -1 & 90.24 \\
\hline 6 & 0 & 0 & 1 & -1 & 88.76 \\
\hline 7 & 0 & 0 & -1 & 1 & 90.12 \\
\hline 8 & 0 & 0 & 1 & 1 & 90.74 \\
\hline 9 & -1 & 0 & 0 & -1 & 88.72 \\
\hline 10 & 1 & 0 & 0 & -1 & 90.41 \\
\hline 11 & -1 & 0 & 0 & 1 & 89.71 \\
\hline 12 & 1 & 0 & 0 & 1 & 91.02 \\
\hline 13 & 0 & -1 & -1 & 0 & 87.25 \\
\hline 14 & 0 & 1 & -1 & 0 & 90.99 \\
\hline 15 & 0 & -1 & 1 & 0 & 87.95 \\
\hline 16 & 0 & 1 & 1 & 0 & 89.65 \\
\hline 17 & -1 & 0 & -1 & 0 & 88.07 \\
\hline 18 & 1 & 0 & -1 & 0 & 90.35 \\
\hline 19 & -1 & 0 & 1 & 0 & 88.44 \\
\hline 20 & 1 & 0 & 1 & 0 & 89.29 \\
\hline 21 & 0 & -1 & 0 & -1 & 87.44 \\
\hline 22 & 0 & 1 & 0 & -1 & 91.33 \\
\hline 23 & 0 & -1 & 0 & 1 & 89.66 \\
\hline 24 & 0 & 1 & 0 & 1 & 91.11 \\
\hline 25 & 0 & 0 & 0 & 0 & 91.31 \\
\hline 26 & 0 & 0 & 0 & 0 & 91.34 \\
\hline 27 & 0 & 0 & 0 & 0 & 91.37 \\
\hline 28 & 0 & 0 & 0 & 0 & 91.35 \\
\hline 29 & 0 & 0 & 0 & 0 & 91.37 \\
\hline
\end{tabular}




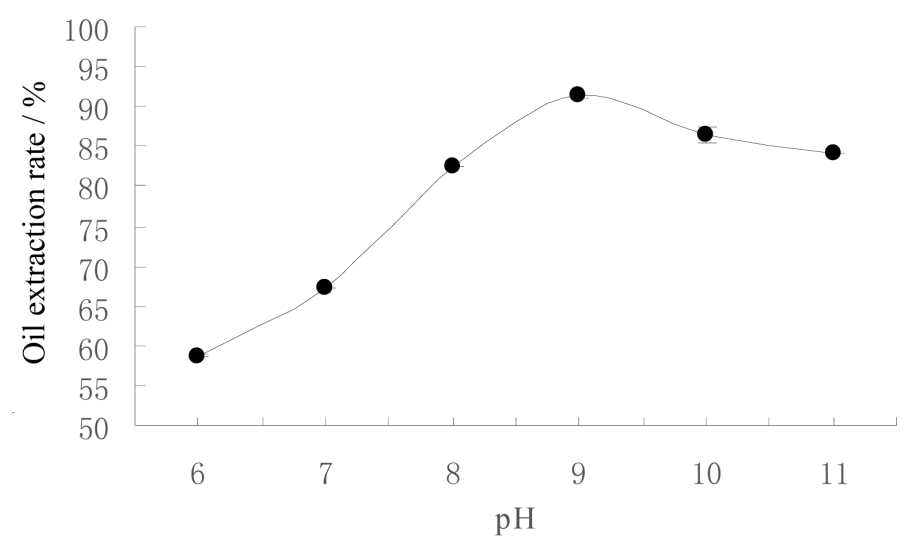

Figure 9. The effects of $\mathrm{pH}$ on extraction of kiwi fruit seed oil.

Table 3. Analysis of variance for the experimental results.

\begin{tabular}{|c|c|c|c|c|c|c|}
\hline Source of variation & Quadratic sum & Degree of freedom & Variance & F value & Prob $>$ F & Significance \\
\hline Model & 575.76 & 14 & 41.13 & 23.49 & $<0.0001$ & ** \\
\hline $\mathrm{X} 1$ & 113.34 & 1 & 113.34 & 64.75 & $<0.0001$ & ** \\
\hline $\mathrm{X} 2$ & 3.91 & 1 & 3.91 & 2.23 & 0.1572 & \\
\hline X3 & 136.82 & 1 & 136.82 & 78.16 & $<0.0001$ & ** \\
\hline $\mathrm{X} 4$ & 4.19 & 1 & 4.19 & 2.39 & 0.1442 & \\
\hline $\mathrm{X} 1 \mathrm{X} 2$ & 1.51 & 1 & 1.51 & 0.86 & 0.3683 & \\
\hline X1X3 & 10.50 & 1 & 10.50 & 6.00 & 0.0281 & * \\
\hline $\mathrm{X} 1 \mathrm{X} 4$ & 26.83 & 1 & 26.83 & 15.33 & 0.0016 & ** \\
\hline $\mathrm{X} 2 \mathrm{X} 3$ & 17.68 & 1 & 17.68 & 10.10 & 0.0067 & $* *$ \\
\hline $\mathrm{X} 2 \mathrm{X} 4$ & 7.73 & 1 & 7.73 & 4.41 & 0.0542 & \\
\hline $\mathrm{X} 3 \mathrm{X} 4$ & 0.15 & 1 & 0.15 & 0.085 & 0.7753 & \\
\hline $\mathrm{X} 12$ & 99.81 & 1 & 99.81 & 57.01 & $<0.0001$ & \\
\hline $\mathrm{X} 22$ & 55.45 & 1 & 55.45 & 31.68 & $<0.0001$ & \\
\hline X32 & 180.50 & 1 & 180.50 & 103.11 & $<0.0001$ & \\
\hline $\mathrm{X} 42$ & 13.62 & 1 & 13.62 & 7.78 & 0.0145 & \\
\hline Residual error & 24.51 & 14 & 1.75 & & & \\
\hline Lack of fit & 21.65 & 10 & 2.16 & 3.03 & 0.1486 & \\
\hline Pure error & 2.86 & 4 & 0.72 & & & \\
\hline Ttotal dispersion & 600.27 & 28 & & & & \\
\hline $\begin{array}{c}\text { correlation } \\
\text { coefficient (R2) }\end{array}$ & 0.9592 & & & & & \\
\hline $\begin{array}{l}\text { Adjusted determination } \\
\text { coefficient (Radj2) }\end{array}$ & 0.9183 & & & & & \\
\hline
\end{tabular}

Note: ${ }^{* *}$ Means extremely significant $(P<0.01),{ }^{*}$ Means significant $(0.01<P<0.05)$. 


\subsection{Analysis of Pattern on Response Surface}

Fix any 2 factors among enzyme amount (X1), $\mathrm{pH}$ (X2) enzymolysis temperature (X3) and enzymolysis time (X4) on level 0 , get the response surface and contour map of the interaction of other 2 factors. The result is as Figures 10-12, the contour is oval, which means there is strong interaction among different factors, the more intensive the contour distributes, the more greatly the factor influences the response value. The contour in the same oval area refers to the same response value, the closer it is to the center, the larger the response value [12]. Enzyme amount (X1), enzymolysis temperature (X3) and enzymolysis time (X4) can all produce best response value in the selected range, which means the selection of factor and the test range is reasonable and effective.

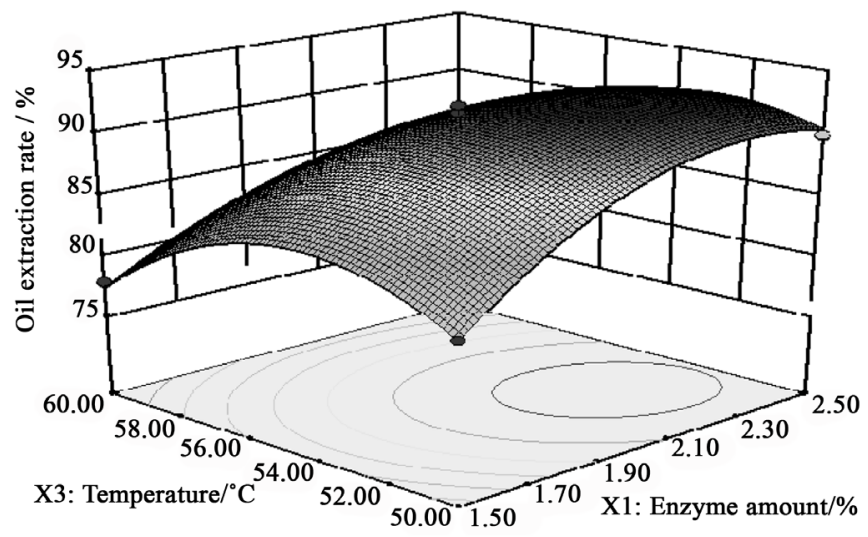

Figure 10. Respinse surface and contour plots of the interactive effects of X1, X3 on the oil yield.

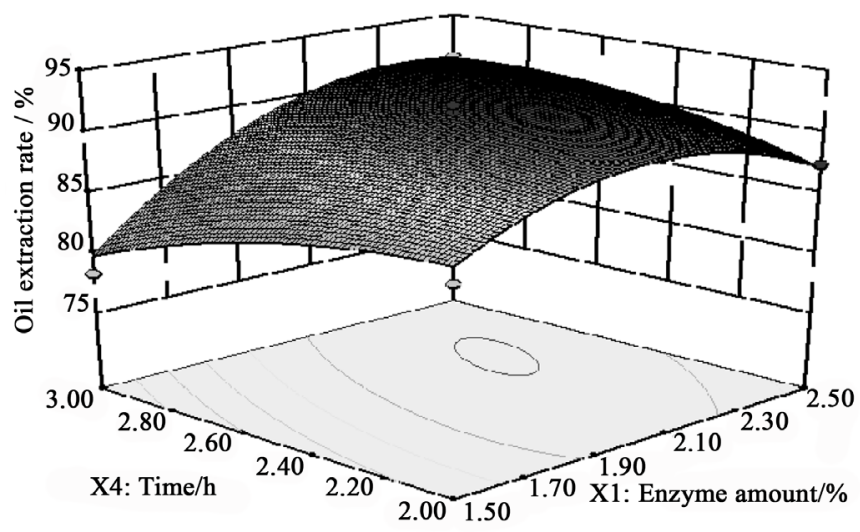

Figure 11. Respinse surface and contour plots of the interactive effects of X1, X4 on the oil yield.

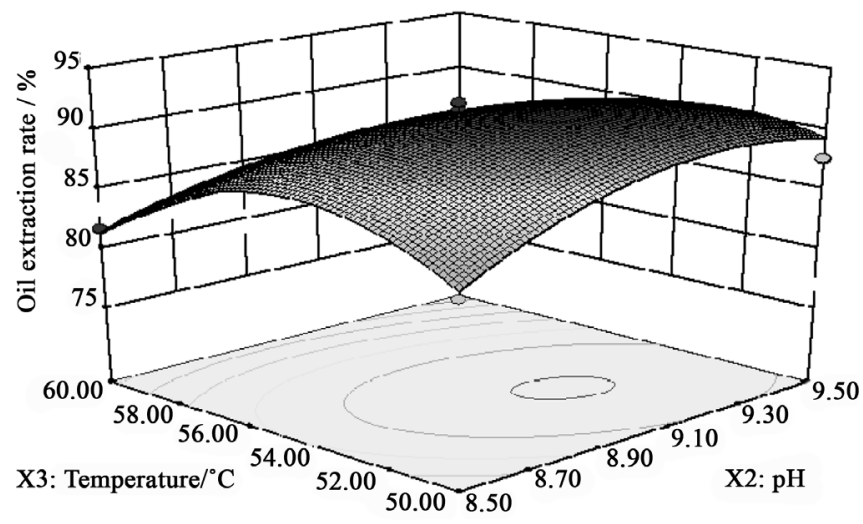

Figure 12. Respinse surface and contour plots of the interactive effects of X2, X3 on the oil yield. 


\subsection{Forecast and Test of the Best Industrial Condition}

Based on analysis of regression model with the method of optimizing analyzing method, and the best response result: the enzyme amount is $2.50 \%, \mathrm{pH}$ is 9.13 , enzymolysis temperature is $52.33^{\circ} \mathrm{C}$, enzymolysis time is $2.80 \mathrm{~h}$, and the theoretical extraction rate is $92.682 \%$. Considering the practical situation, set enzyme amount as $2.50 \%$, $\mathrm{pH}$ as 9.2, enzymolysis temperature as $53^{\circ} \mathrm{C}$, enzymolysis time as $2.80 \mathrm{~h}$, conduct 3 parallel verification tests under this condition to reduce error, and the average extraction rate is $92.57 \%$. Compared to theoretical value, the relative error is $0.121 \%$, which verifies the feasibility of the regression model.

\section{Conclusion}

Based on single-factor test, Box-Behnken test design, and response surface analysis, this paper optimized the technology of extracting kiwi fruit seed oil with ultrasonic-assisted enzyme and response surface method, the best industrial condition: material granularity: 60, liquid-to-solid ratio: 1:10 (g/mL), ultrasonic power: 400 W, treating time: $30 \mathrm{~min}$, enzyme amount: $2.50 \%, \mathrm{pH}: 9.2$, enzymolysis temperature: $53^{\circ} \mathrm{C}$, enzymolysis time: 2.80 $\mathrm{h}$, and the extracting ratio under such condition is $92.57 \%$. Compared to theoretical value, the relative error is $0.121 \%$, which proves that the model is reasonable and reliable with certain practical value.

\section{Fund Project}

Jointly funded by project of "Heilongjiang forest economic source development and use innovation center" and pilot project of reform of excellent forestry talent education training funding plan (41110211).

\section{References}

[1] Yao, M.J., Li, J.X., et al. (2001) Discussion on Development and Use of Kiwi Fruit Seed Oil. Food and Fermentation Industry, 27, 28-29.

[2] Ni, P.D. and Jiang, Z.W. (2002) New Technology of Preprocessing Oil Making with Aqueous Enzymatic Method. China Oils and Fats, 27, 5-8.

[3] Ma, Y., Guo, J.X., Wang, Q., et al. (2010) Research on Technology of Extracting Sweet Almond Oil with Aqueous Enzymatic Method. Food and Machinery, 26, 145-147.

[4] Chi, X.X. and Zhao, D.X. (2010) Research on Extracting Sunflower Seed Oil with Aqueous Enzymatic Method. Journal of the Chinese Cereals and Oils Association, 25, 71-73.

[5] Huang, L.H., Zhang, X.Y. and Ni, X.Y. (2010) Research on Extracting Walnut Oil with Aqueous Enzymatic Method. Grain Science and Technology and Economy, 35, 30-32.

[6] Li, J.X., Sun, J.Y., Liu, F., et al. (2010) Optimization of Technology of Extracting Kiwi Fruit Seed Oil with UltrasonicAssisted Method. China Oils and Fats, 35, 11-14.

[7] Zhang, G.D., Luo, C.X., Fu, C., et al. (2005) Optimizing Ultrasonic Extracting Technology of Kiwi Fruit Seed Oil with Uniform Design. Grain and Oil Processing \& Food Machinery, 1, 54-55.

[8] Wu, D., Liu, C.P., Gao, Y.L., et al. (2008) Research on Operation Unit of Wheat-Germ Oil with Immobilized Enzyme. Food Science, 29, 339-341.

[9] Yang, L., Jiang, L.Z., Li, Y., et al. (2009) Research on Extracting Soybean Oil with Ultrasonic-Assisted Aqueous Enzymatic Method. China Oils and Fats, 34, 10-13.

[10] Huang, Y. and Wu, P. (2006) Analysis and Application of SAS Statistics. China Machine Press, Beijing, 202-252.

[11] Ran, X.Y., Dong, H.Z., Liu, C.F., et al. (2011) Research on Optimization and Physicochemical Property of Maize Extrusion Technical Condition. Journal of Chinese Institute of Food Science and Technology, 7, 140-147.

[12] Wu, G.J., Li, Y.P. and Pi, X.F. (2010) Optimization of Extracting Technology of Portulace Oleracea Polysaccharide with Response Surface. Food Industry Machinery, 26, 129-133. 


\section{Submit or recommend next manuscript to SCIRP and we will provide best service for you:}

Accepting pre-submission inquiries through Email, Facebook, LinkedIn, Twitter, etc.

A wide selection of journals (inclusive of 9 subjects, more than 200 journals)

Providing 24-hour high-quality service

User-friendly online submission system

Fair and swift peer-review system

Efficient typesetting and proofreading procedure

Display of the result of downloads and visits, as well as the number of cited articles

Maximum dissemination of your research work

Submit your manuscript at: http://papersubmission.scirp.org/ 